\title{
Racismo, colonialidade e descolonização do currículo formal: duas experiências no chão da escola e a fuga de uma história única
}

\begin{abstract}
Resumo:
O objetivo deste artigo é refletir sobre o racismo e a história única que impera na educação brasileira, a partir de uma discussão teórica sobre duas experiências vividas pelo pesquisador, como professor negro, em duas escolas de diferentes regiões brasileiras: a escola quilombola Colégio Estadual Onildo Raimundo de Cristo (BA) e o Instituto Federal de Educação, Ciência e Tecnologia de Mato campus Primavera do Leste (MT). Apesar de apresentarem histórias e trajetórias distintas, de serem projetadas para públicos diferentes, procedeu-se à reflexão sobre aquilo que essas escolas têm em comum, que é urgência da descolonização do currículo formal, das práticas educativas e pedagógicas, em favor de um fazer decolonial radical, preparado para lidar com as necessidades de uma educação antirracista que dialogue com as demandas reais da sociedade brasileira. Concluiu-se que é premente a necessidade de superar a colonialidade existente na educação, promovendo um fazer decolonial que possa ser construído para além de uma história única.
\end{abstract}

\section{Palavras-chave:}

Lógica colonial. Colonialidade. Racismo epistemológico.

\begin{abstract}
:
The objective of this article is to reflect on racism and the single story that prevails in Brazilian education, from a theoretical discussion about two experiences lived by the researcher, as a Black teacher, in two schools in different Brazilian regions: the quilombola school Colégio Estadual Onildo Raimundo de Cristo (BA) and the Instituto Federal de Educação, Ciência e Tecnologia de Mato Grosso - campus Primavera do Leste (MT). Despite they present different histories and trajectories, and have designed for different audiences, it was possible to make a reflection on what these schools have in common, which is an urgent need to decolonize the formal curriculum, educational and pedagogical practices, in favour of a radical decolonial practice, prepared to deal with the needs of an anti-racist education that dialogs with the real demands of Brazilian society. It was concluded that there is an urgent necessity to overcome the existing coloniality in education, promoting a decolonial practice that can be built beyond a single story.
\end{abstract}

\section{Keywords:}

Colonial logic. Coloniality. Epistemological racism.

\footnotetext{
* Graduado em História pela Universidade Federal do Recôncavo da Bahia; mestre em História Social pela Universidade Federal da Bahia; doutorando em História na UFMT; professor EBTT de História no Instituto Federal de Mato Grosso. E-mail: lucas.cafe@pdl.ifmt.edu.br. ORCID iD: https://orcid.org/0000-0003-2654-0788.
} 


\section{Introdução}

No artigo "Para descolonizar os estudos de economia política e os estudos pós-coloniais: transmodernidade, pensamento de fronteira e colonialidade global”, Ramón Grosfoguel (2008) afirma que a expansão colonial europeia significou o genocídio e o epistemicídio de indígenas, de africanos e de mulheres. Além disso, o colonialismo realizou um enorme memoricídio, haja vista que a estrutura de conhecimento que domina as universidades de todo o mundo está atrelada à estrutura imperialista colonial de poder. Dessa forma, podemos dizer que a educação que impera nas escolas de todo o mundo está impregnada de valores e concepções racistas que marginalizam a diferença, colocando-a como antieducação e anticonhecimento.

No Brasil, a lógica colonial não apenas buscou dizimar as pedagogias ancestrais, indígenas, africanas e afro-brasileiras, como também silenciou e tenta silenciar até hoje qualquer tipo de prática pedagógica antirracista. É o homem ocidental, europeu, branco, heterossexual, cristão, quem decide o que é o melhor para as demais populações de todo mundo. Segundo Grosfoguel (2008), autores homens, brancos, de cinco países do mundo formam os cânones da ciência desenvolvida em qualquer universidade do mundo. Isso revela um racismo e um sexismo epistemológicos iniciados com a modernidade e o colonialismo. Dessa forma, para decolonizar o pensamento, é necessário dialogar com uma diversidade epistêmica, buscando enriquecer a maneira de ver o mundo.

Sem o diálogo com a diversidade epistêmica, é impossível romper com a lógica colonial que existe na educação e é expressa por meio do currículo escolar formal de quase todo mundo colonizado. A permanência desse tipo específico de colonialismo entre nós acontece devido ao atual estado de colonialidade em que vivemos. Falando da América Latina como um todo, Aníbal Quijano (2005) afirma que, apesar desta não ser mais uma colônia da Europa, apesar do colonialismo como período histórico ter chegado ao fim no início do século XIX, atualmente ainda sofremos com a dominação europeia e vivemos um momento chamado de colonialidade.

A colonialidade é percebia na persistente hierarquização entre os seres humanos, assim como, nas classificações e estratificações que são impostas a suas produções culturais e materiais. Essas divisões fazem com que, ainda hoje, os conhecimentos das populações historicamente marginalizadas sejam alijados da educação formal. O abismo que separa as produções culturais e os saberes dos colonizadores dos saberes dos colonizados teve como ponto fundante o conceito de raça.

É da ideia de raça e do racismo estrutural e epistemológico que surge a naturalização da superioridade dos saberes e das práticas pedagógicas europeias sobre as demais. A construção mental de raça é motor da criação de um imaginário social que despreza as produções culturais das populações minoritárias em direitos e em cidadania, e essas populações, no Brasil, de longe, são a maioria.

O racismo é um problema global e não local. Compreendê-lo como um fenômeno mundial que, em cada espaço, desenvolve especificidades próprias é uma premissa essencial para superá-lo. Não podemos pensar o racismo como um fenômeno de determinados lugares do país ou de poucos espaços isolados no mundo. A partir da ideia de colonialidade, do conceito de raça e da história global, percebemos que o racismo é um fenômeno que estrutura sociedades de todos os continentes, que ajuda a determinar políticas públicas, econômicas e sociais, as quais afetam a vida de bilhões de pessoas em todo planeta.

Segundo Sebastian Conrad (2016), a história global não é a história de tudo, mas é uma história que transcende a ideia das fronteiras nacionais, buscando entender as relações existentes entre as diferentes sociedades, ou como, em diferentes momentos, diferentes sociedades se inter-relacionaram. Para ele, a história global tem limites de aplicação, ou seja, não é possível aplicar em todos os casos, em todos os tempos e em todos os lugares, mas é importante para entender como impera em todo mundo contemporâneo um ideal racista que legitima uma "história única" (ADICHIE, 2019) sobre as populações marginalizadas que se eternizam no chão da escola. A perspectiva da história global é, ao meu ver, importante para se entender o processo de dominação colonial, a colonialidade e o racismo como fenômenos globais que ainda hoje marginalizam conhecimentos e eliminam as diferenças no Brasil e no mundo, tendo a educação como aliada histórica desse processo de dominação e exploração. 
A noção de história única vem sendo pensada e desenvolvida por uma série de autores/as ao longo dos séculos de XX e XXI. Tais estudiosos/as buscaram de alguma forma criticar o princípio da existência de uma história universal a partir da universalização da história oficial e da história das elites. Nesse texto, buscamos dialogar com a noção de história única a partir da problematização do conceito de história proposta por Walter Benjamin (1985) e pela noção desenvolvida por Chimamanda Ngozi Adichie (2019), escritora nigeriana que popularizou recentemente a noção de história única no meio acadêmico internacional, sobretudo, entre o feminismo negro e o pensamento afro-diaspórico.

Em diálogo com a história global, Quijano (2005, p. 117) afirma que é impossível entender o racismo na América Latina sem entender a globalização: "A globalização em curso é, em primeiro lugar, a culminação de um processo que começou com a constituição da América e do capitalismo colonial/moderno e eurocentrado como um novo padrão de poder mundial”. Segundo Quijano, um dos eixos

[...] fundamentais desse padrão de poder é a classificação social da população mundial de acordo com a ideia de raça, uma construção mental que expressa a experiência básica da dominação colonial e que desde então permeia as dimensões mais importantes do poder mundial, incluindo sua racionalidade específica, o eurocentrismo. (QUIJANO, 2005, p. 117).

Essa classificação ou essa hierarquização tem uma origem e um caráter colonial. Porém, mostrou ser mais duradoura “[...] e estável que o colonialismo em cuja matriz foi estabelecido. Implica, conseqüentemente, num elemento de colonialidade no padrão de poder hoje hegemônico" (QUIJANO, 2005, p. 117).

Para Quijano (2005), a construção da categoria mental de raça foi essencial para a dominação europeia na América e, posteriormente no resto do mundo. Não é possível entender o processo de dominação europeu que se reflete em nosso fazer pedagógico sem entender a construção da ideia de raça. Foi a partir dessa divisão social que foi possível pensar e executar os processos de conquista e exploração. A cultura ocidental se sustenta em uma relação de dominação cujo maior trunfo é a colonização do imaginário do colonizado, que também foi racializado. Ainda para esse autor, ninguém consegue ser explorado se não for dominado. E a dominação se deu a partir do processo de racialização. Dessa forma, dominar ou controlar, ou seja, colonizar os conhecimentos e as formas de pensar do colonizado, constituiu-se como um papel essencial no processo de dominação (QUIJANO, 1992).

Avançando no conceito de colonialidade de Aníbal Quijano, a partir da perspectiva da história global, Walter Mignolo (2017) afirma que a colonialidade era a pauta oculta ou o lado "escuro" da modernidade. Segundo o autor, pensar o conceito de colonialidade já é um ato descolonizador, pois é preciso partir de um olhar decolonial para observar a barbárie existente por trás do discurso civilizatório. “Assim, ocultadas por trás da retórica da modernidade, práticas econômicas dispensavam vidas humanas, e o conhecimento justificava o racismo e a inferioridade de vidas humanas, que eram naturalmente consideradas dispensáveis" (MIGNOLO, 2017, p. 4). Dessa forma, a partir da visão de Mignolo, podemos pensar que, por trás do discurso de progresso e de desenvolvimento, estão práticas discursivas e representações que tiram vidas, dizimam memórias e exterminam culturas.

Grosfoguel (2008), Quijano (2014) e Mignolo (2017) concordam que a principal tarefa dos/as teóricos/ as decoloniais é quebrar com a colonialidade existente no mundo, colonialidade esta travestida de globalização/modernidade, conforme assinala Quijano (2014, p. 767):

Hay un hecho en la cultura de América toda, y en la de América Latina en particular, que implica a todo el mundo de hoy en su globalidad y que precisa ser reconocido, puesto en cuestión, debatido y evacuado: la colonialidad del poder. Ese es el primer paso en dirección de la democratización de la sociedad y del Estado; de la reconstitución epistemológica de la modernidad; de la búsqueda de una racionalidad alternativa. 
E quebrar a colonialidade significa utilizar a diversidade epistêmica.

Em ambos os casos, a geopolítica e a corpo-política (entendidas como a configuração biográfica de gênero, religião, classe, etnia e língua) da configuração de conhecimento e dos desejos epistêmicos foram ocultadas, e a ênfase foi colocada na mente em relação ao Deus e em relação à razão. Assim foi configurada a enunciação da epistemologia ocidental, e assim era a estrutura da enunciação que sustentava a matriz colonial. Por isso, o pensamento e a ação descoloniais focam na enunciação, se engajando na desobediência epistêmica e se desvinculando da matriz colonial para possibilitar opções descoloniais - uma visão da vida e da sociedade que requer sujeitos descoloniais, conhecimentos descoloniais e instituições descoloniais.

O pensamento descolonial e as opções descoloniais (isto é, pensar descolonialmente) são nada menos que um inexorável esforço analítico para entender, com o intuito de superar, a lógica da colonialidade por trás da retórica da modernidade, a estrutura de administração e controle surgida a partir da transformação da economia do Atlântico e o salto de conhecimento ocorrido tanto na história interna da Europa como entre a Europa e as suas colônias, como veremos a seguir. Escusado será dizer que nenhum livro sobre a descolonialidade fará diferença, se nós (intelectuais, estudiosos, jornalistas) não seguirmos a vanguarda da sociedade política global emergente (os denominados “movimentos sociais"). (MIGNOLO, 2017, p. 6).

A crítica decolonial, ao utilizar as ferramentas de análise da história global, ajuda-nos a pensar o racismo no Brasil para além de um problema nacional, mas como um problema global que ganha força graças à colonialidade. Isso não impede que possamos investigar algumas especificidades do racismo brasileiro e as formas como o racismo se constituiu no Brasil. Porém, não podemos perder de vista o racismo como um paradigma que ultrapassa as fronteiras nacionais. Nesse sentido, o que fez nascer este artigo foram as experiências vividas durante a vida de educador em duas cidades e estados diferentes e intencionou refletir sobre diferentes experiências do chão da escola, uma como um novato que precisava aprender com os quilombolas; e outra, certo tempo depois quando procurado para resolver questões pedagógicas que os gestores tinham dúvidas sobre como agir.

Iremos, pois, refletir sobre o racismo, o currículo escolar e a opção decolonial antirracista para superação do epistemicídio escolar e, consequentemente, para a efetivação de uma educação antirracista voltada para a superação do racismo e das hierarquizações, estratificações e classificações existentes na sociedade.

\section{Experiências de uma narrativa única em uma escola quilombola na Bahia ${ }^{1}$}

Abril de 2012. Era minha primeira experiência como professor efetivo em uma escola pública da rede estadual da Bahia. O momento era vivido com muita intensidade por toda família. As expectativas eram grandes, pois, pela primeira vez, tínhamos em nosso círculo alguém que havia ingressado no ensino superior e concluído os estudos. Em nosso lar, esse fato era extremamente representativo, ou, por que não, revolucionário. Pensem na emoção de avós analfabetos vendo o neto letrado. O primeiro entre várias gerações a conseguir realizar um sonho coletivo ao se tornar um professor diplomado. Reflitam sobre a emoção de um pai, trabalhador rural, que estudou até a $5^{\circ}$ série, e, aos 18 anos, seu maior sonho era comprar uma bicicleta quebrada, vendo um de sua prole se tornar educador. Imaginem a felicidade de uma mãe, feirante, que viu o filho sair do balcão da feira livre para ser "protagonista" nos bancos escolares.

Uma experiência que deveria ser comum e corriqueira em outras casas, na nossa, significava uma mudança de rumo. Era nada mais nada menos que uma nova história que se desenhava na vida daqueles sujeitos. Contrariando as narrativas triunfalistas racistas que imperam no imaginário das periferias, tínhamos ali um jovem negro, de família pobre, que estava alcançando o sucesso em sua empreitada de buscar um "lugar ao sol".

1. Nesta seção, utilizaremos, em alguns momentos do texto, a 1a pessoa do singular para discorrer sobre as experiências vividas nas escolas, locus de estudo desta pesquisa. 
E minha primeira experiência como professor não foi em uma escola qualquer. Aos 24 anos, fui o primeiro e único professor efetivo a tomar posse na escola quilombola Colégio Estadual Onildo Raimundo de Cristo. O primeiro, porque a escola era nova, recém-inaugurada para atender aos estudantes do Orobó, uma região rural quilombola de Valença, cidade litorânea, localizada no baixo-sul da Bahia. E o único, pelo motivo de nenhum/a outro/a professor/a querer tomar posse para trabalhar em uma escola quilombola de zona rural, $30 \mathrm{~km}$ afastada do centro da cidade, cujo acesso se dá por estrada de chão, que, durante o inverno, vira um lamaçal e, no verão, formam-se "crateras lunares".

Se pretendemos desnaturalizar os processos e propor uma ideia que seja para além de uma história única, não podemos deixar margem para ingenuidades. Existe uma história única sobre as populações quilombolas e rurais brasileiras, que não é traduzida tão somente pela falta de direitos civis e sociais, cuja ausência, segundo José Murilo de Carvalho (2002, p. 9), faz com que essas populações vivam como cidadãos incompletos ou até mesmo como não-cidadãos.

Essa história única e preconceituosa sobre as comunidades tradicionais também impera no imaginário da população comum, e é possível identificá-la, por exemplo, na mente de professores que se recusam a trabalhar em escolas rurais, sobretudo quilombolas, e se utilizam de desculpas generalizantes, cujo teor é adubado pelo racismo estrutural.

Antonio Sérgio Alfredo Guimarães (1999, p. 11) explica que o racismo pode ser entendido como "uma forma bastante específica de 'naturalizar' a vida social, isto é, de explicar diferenças sociais e culturais a partir de diferenças tomadas como 'naturais'". Naturalizado, o racismo é disseminado em nossa sociedade, sendo praticado de forma consciente e inconsciente.

O comportamento racista é identificado nos/nas que se negam a trabalhar em uma escola quilombola, mas também naqueles/as que, quando estão trabalhando nessas comunidades, acreditam que são os/as únicos/as detentores do conhecimento e provedores da verdade. Destarte, a história única pode se vestir de diferentes e várias roupagens, desfilando de forma diversa na passarela da escola.

Em minha própria família, havia os/as que não aceitavam o fato de um filho, que se graduou em uma universidade federal, e estava prestes a concluir um mestrado em outra, ser aprovado em um concurso público muito concorrido, e como resultado de todo esforço, acabar trabalhando na "roça" juntos com os "quilombolas". Esse pensamento preconceituoso e racista só pode ser comum em uma família de negros, só pode ser reproduzido sem o mínimo de constrangimento, pelo fato de existir uma naturalização de elementos colonizadores noviços na vida social brasileira, sobretudo, da permanência do racismo, traduzido na naturalização das classificações e hierarquizações sobre os seres humanos existentes na sociedade brasileira (GUIMARÃES, 1999). Em síntese, esse discurso no seio de uma família negra revela a força do imaginário social, sob o qual todos estão submetidos porque é força cristalizadora e institucionalizada. Por que uma família negra teria de agir diferente se lhe foi ensinado a pensar dessa forma?

Essa naturalização maléfica, que ocorria naquele ambiente, afetava diretamente os/as quilombolas, que não queriam ser reconhecidos/as por esse termo e não desejavam criar ou ter nenhuma relação de identidade com a terminologia. Quilombola, era tudo que as pessoas - quilombolas - do Orobó não queriam ser.

Poucos eram os/as que, por questões políticas, identificavam-se com a palavra e, ao fazer isso, também assinavam um contrato com a discriminação, uma vez que, assumir-se quilombola, significava ser cada vez mais racializado/a e estigmatizado/a (até mesmo na comunidade).

No primeiro dia de aula, também momento da inauguração da escola, pude observar vários acontecimentos, sobre os quais já havia lido e estavam sendo colocadas à prova. A inauguração aconteceu pela manhã, com a presença de várias autoridades, que nunca mais pisaram seus pés na comunidade - e também no prédio escolar. Eram pessoas que foram somente para a solenidade, uma forma de serem vistas e de se mostrarem. A população (pais, responsáveis, estudantes, colaboradores da escola etc.) também estava presente e muito feliz, uma vez que a inauguração de uma instituição que ofertasse o ensino médio era a realização de um grandioso sonho.

Entretanto, o nome da escola não homenageava um general, um coronel ou um prefeito qualquer, como é comum no Brasil, mas sim um cidadão conhecido na região e tido como herói por todos, pois, 
durante toda a sua vida, defendeu a comunidade em busca de valorização e reconhecimento dos trabalhos ali desenvolvidos, como a produção agrícola (cravo, cacau, guaraná, banana, urucum etc.).

Onildo Raimundo de Cristo era conhecido por ser um homem que não tinha medo de falar. Era aquele que ia na rádio defender o Orobó e seu povo. Entre outras palavras, o homenageado parecia ser uma pessoa que questionava a história única, não aceitando os lugares predeterminados que a sociedade afirmava que ele, como quilombola, deveria ocupar.

Durante a inauguração, fui convidado para fazer uma fala de recepção e boas-vindas aos estudantes. $\mathrm{Na}$ oportunidade, referenciei a questão da identidade e me apresentei como alguém que iria lutar para dar voz àquelas pessoas que, historicamente, eram excluídas da democracia e, portanto, não gozavam da cidadania. Estava tomado pela euforia e pelo desejo de poder transformar vidas. Sentia, naquele momento, como se fosse uma espécie de vanguarda revolucionária.

Imbuído de um sentimento de transformação, naquele "esperançar" freiriano (FREIRE, 2014), não fui capaz de perceber que não se precisava dar voz àquela comunidade, uma vez que voz aquelas pessoas tinham e sempre tiveram. Na verdade, o que elas precisavam era ser ouvidas. É no silêncio de quem ouve e não na mudez de quem fala que está a raiz do problema. Na época, não entendia que, como aborda Djamila Ribeiro (2019), é impossível falar "por". Descobri depois, e isso se deu pela experiência e trabalho naquela escola, que o caminho do diálogo se dá pelo ouvir, pelo aprender e pelo falar "com".

Os estudantes pareciam, o que fui aos poucos sentindo, não receber bem aquela fala que expressava uma vontade nutrida por uma abundante militância política. A questão da identidade rural e quilombola não era algo que agradava aos ouvintes. Várias expressões de discordância puderam ser vistas a partir do que foi enunciado. Aquelas pessoas estavam incomodadas pelo fato de alguém querer falar por elas, indicar-lhes caminhos que elas deveriam seguir de agora em diante. Percebi, naquele mesmo momento, que o discurso não soava agradável, mas tinha a crença de que isso acontecia devido ao nível de alienação que acometia toda aquela gente.

À noite, realizamos nossa primeira aula na escola. O primeiro contato foi com uma turma da Educação de Jovens e Adultos, público majoritariamente de mulheres negras. Havia estudantes de diversas faixas etárias, sendo que cerca de $90 \%$ da turma tinha idade acima da minha. O meu discurso militante "salvacionista" permaneceu durante a aula. Diante daqueles estudantes, expus que se iniciava uma nova era dentro do Orobó, porque a inauguração da escola representava uma mudança de rumos na história da comunidade quilombola. Era o que eu acreditava.

Falar antes de ouvir é um equívoco cometido com frequência por professores/as, sobretudo, pelos/as mais jovens. A influência da educação tradicional e bancária nos faz acreditar que somos detentores da verdade. No caso dos/das professores/as de História, somos influenciados ainda pela crença de uma história única, teleológica, etapista, progressista e predeterminada. Ao chegar com meu discurso salvacionista, nem parei para pensar no que realmente aquelas pessoas deveriam ser salvas. Porém, logo percebi que uma das coisas que elas queriam se salvar era do meu discurso enviesado e excludente.

Naquele espaço, onde a sociedade só enxergava "roceiros", eu via professores/as, médicos/as, engenheiros/as, advogados/as, administradores/as em futuro muito próximo. Foi então que a fala de um estudante, de aproximadamente 40 anos, provocou uma importante reflexão sobre qual seria o papel e lugar do professor naquela comunidade. Afirmava ele que eu parecia um pastor querendo pregar uma verdade a ser seguida. Pontuou que o discurso era vazio e soava aos ouvidos como falacioso, pois não tinha conhecimento sobre a realidade que eles viviam no interior daquela comunidade. Continuou dizendo que uma coisa era o que se aprendia nos livros, e outra era o que a vida tinha lhes ensinado.

A interpelação me deixou abalado. Fui pego de surpresa; solicitei, no entanto, que o estudante continuasse e explicasse o que era que a vida havia lhes proporcionado de experiência. Pensei em Paulo Freire naquele momento.

O estudante, então, fez um relato de como a história única é nociva para a construção de uma sociedade plural e humanitária. As palavras cantadas por ele denunciavam as dificuldades vividas, apontavam para ausência de direitos civis e sociais, para uma vida marcada pela opressão política, pela dominação 
econômica e para a hierarquização sociorracial. Lembrou também que outros arautos da liberdade já haviam aparecido por lá com a promessa de transformar a vida dos quilombolas, mas depois desapareciam como neblina ao esquentar do sol.

Esses arautos, lembrava ele, eram pesquisadores que estudavam a comunidade, diziam para todos ali que eles eram quilombolas e, por isso, tinham uma série de direitos a serem reivindicados. Produziam vídeos, faziam fotos, realizavam entrevistas e faziam uma série de promessas. Promessas vazias de quem quer "falar por" e não "falar com". Depois sumiam.

Abdias do Nascimento (1978) chama a atenção para esse tipo de desvio cometido por pesquisadores/ as, geralmente brancos/as ou europeus/eias, das classes médias e altas, que, ao trabalhar com comunidades tradicionais, folclorizam suas culturas e transformam os atores sociais em objeto. $\mathrm{O}$ estudante, portanto, em outras palavras, dialogava com Abdias e analisava o meu comportamento, similar àqueles que por ali passaram, que levavam de tudo e nada deixavam.

Para o estudante, não havia diferença entre um coronel, um político tradicional, um professor e um pesquisador. Todos apareciam apenas para ditar regras, para definir o que era certo e o que era errado. Chegavam para apontar suas verdades. Enfim, todos chegavam criando aquilo que Boaventura de Sousa Santos (2009, p. 24) denomina "linhas abissais".

Em tom de desabafo, questionou o fato de ter falado sobre a chegada de uma nova era que transformaria a vida da comunidade ao lhes impor novas "oportunidades". No questionamento, ele apontou que a população deveria ser reconhecida e respeitada como era, ou seja, como uma comunidade tradicional de agricultores/as, com conhecimento e histórias de vida, não deveria ser necessário que eles/as se transformassem em médicos/as, advogados/as ou engenheiros/as para que passassem a ser consideradas pessoas com dignidade.

Por fim, o estudante falou que estava cansado de promessas e ilusões, afirmando que a escola funcionaria mais como um passatempo ou como ponto de encontro para a população, servindo, no máximo, para que conseguissem um diploma e se orgulhassem da conclusão do ensino médio. A realidade em que eles viviam apontava para algumas verdades que podem ser traduzidas pelas palavras silenciamento, dominação e exploração.

Outros/as estudantes também falaram e seguiram a mesma linha de raciocínio do colega. Era preciso receptividade e sensibilidade para compreender aquele momento. Demandas parecidas e diferentes foram apresentadas. Foi o dia em que eu fui para ensinar e saí de lá aluno. Transformei-me em um ser que aprende dialogicamente numa troca de saberes. Era ali que entrava Paulo Freire: aprender mais do que ensinar, ou melhor, ensinar e aprender em conjunto.

Aquelas falas me levaram à conclusão de que, apesar das boas intenções, eu também chegara ali com a ideia de trabalhar numa narrativa excludente, criando linhas abissais. A partir daquele momento, a certeza que tinha é que seria necessário superar, ou seja, desnaturalizar concepções e reconhecer a necessidade de militar por um fazer que pensasse para além de uma história única. Talvez, o caminho mais fértil fosse reconhecer que, naquela comunidade, tinha-se muito mais a aprender do que ensinar e poderia, desse modo, ter a possibilidade de compreender as feridas e dores de uma população que não queria e ainda não quer ser taxada ou limitada por quem quer que fosse.

\section{Versões de uma história única em uma escola federal de educação tecnológica em Mato Grosso}

Agosto de 2016. Uma professora de Língua Portuguesa do Instituto Federal de Mato Grosso - campus Primavera do Leste me convidou para uma reunião. Desejava falar sobre um acontecimento relacionado a uma pesquisa que ela desenvolvia dentro da instituição e envolvia a participação de alguns estudantes do ensino médio. Nos institutos federais, é comum a participação de discentes em projetos de iniciação cientifica e o convite era para conversarmos sobre um caso de racismo que ocorrera durante uma das etapas de seu trabalho.

Em um primeiro momento, a professora procurou a gestão do campus para relatar o acontecido. Porém, acreditando que o trato com o caso talvez não fosse adequado, ela solicitou minha ajuda. 
Dois foram os motivos que contribuíram para que o convite fosse realizado. O primeiro se referia a uma percepção da professora da necessidade de o caso ser refletido com profundidade e por alguém que compreendesse o tema. Quando praticado entre estudantes em ambiente escolar, a discriminação racial geralmente é desconfigurada e vista, muitas vezes, tão somente como simples brincadeira. Dagoberto José Fonseca (2012) mostra como determinadas piadas, brincadeiras e anedotas servem para explicitar a fragilidade da nossa democracia racial, pois, quando se analisa essas situações com o devido cuidado, verifica-se que são veículos importantes de propagação e enraizamento do racismo.

O segundo motivo dizia respeito à cor de minha pele. A professora também me procurou por eu me identificar e por ser negro. Ela partiu de um dos princípios existentes nas relações étnico-raciais no Brasil, a ideia de que só sendo negro para se interessar por "questões de negro". Em uma sociedade marcada pela negação do racismo e pela permanência de uma história única que afirma que não existe discriminação racial, balizada - mais uma vez pelo mito da democracia racial -, a conclusão de muitas pessoas é a de que só sendo negro para se preocupar com o racismo, uma vez que o racismo somente seria preocupação exclusiva da população negra.

Pensar dessa forma é um equívoco, uma vez que as relações étnico-raciais dizem respeito a toda a sociedade. Se negros são marcados negativamente pelo racismo, os brancos serão beneficiados com os privilégios da branquitude. Sendo assim, discutir as relações étnico-raciais é um dever coletivo, pois, se alguém está sendo desprovido de seus direitos devido à cor de sua pele e de suas características fenotípicas, existe alguém que está tirando proveito dessa situação.

$\mathrm{Na}$ reunião com a professora, foi-me detalhado o acontecimento. Em uma pesquisa de opinião, alguns estudantes que faziam parte do projeto tinham a missão de aplicar questionários e realizar entrevistas. O objetivo era mapear as sugestões dos estudantes para a construção de uma escola melhor. Uma das perguntas era bem simples: "O que você gostaria que mudasse em nossa escola para a construção de um ambiente melhor?".

Dois estudantes brancos, de família "sulista", quando foram interpelados por um entrevistador negro (também estudante), não hesitaram: "Queremos que todos os negros sejam retirados de nossa escola. Professores e alunos. Aqui não é lugar de negro. Todos devem sair daqui. Devemos enviar todos de volta para os canaviais e para as senzalas. Estes que são os lugares apropriados para eles. Quando tirarmos todos os negros daqui, teremos uma escola muito melhor".

Não nos chocou tanto a resposta dos estudantes como chocou o possível despreparo da gestão escolar para lidar com o caso. Para os/as negros/as, como nós, acostumados/as a lidar com a discriminação racial nos mais diversos ambientes, acostumados/as a saber que a escola é um espaço por excelência da reprodução do racismo institucional, uma resposta dessa não causa surpresa. Desde pequenos, aprendemos que a discriminação racial e a escola andam de mãos dadas. A surpresa advém do fato de que, em 2016, numa instituição federal de ensino, os profissionais possivelmente não soubessem como lidar com situações de cunho racial.

Ora, se em uma escola existe uma imensa dificuldade de tratar de forma apropriada um caso de racismo, é porque inexiste uma discussão racial naquele ambiente, apesar de haver, desde 2003, uma lei que obriga as instituições de ensino, em todos os níveis (BRASIL, 2003).

Para Gomes e Munanga (2016), a primeira forma de combater o racismo e a discriminação racial é através da legislação penal. Porém, os autores afirmam que a maioria da população brasileira desconhece a legislação que trata sobre as questões raciais no Brasil. Esse desconhecimento também está presente das escolas.

De um modo geral, a população brasileira desconhece também a importância das ações afirmativas que se constituem como políticas de combate ao racismo e à discriminação racial mediante a promoção ativa da igualdade de oportunidades para todos, "criando meios para que as pessoas pertencentes a grupos socialmente discriminados possam competir em mesmas condições de igualdade" (GOMES; MUNANGA, 2016, p. 186). Essas ações podem ser estabelecidas na educação, na saúde, no mercado de trabalho, nos

2. Primavera do Leste é uma das cidades mato-grossenses de colonização sulista, sendo sua elite econômica, política e social composta majoritariamente por descendentes de europeus oriundos da região sul do país, sobretudo do Rio Grande do Sul. 
cargos políticos, entre outros; enfim, continuam os autores a dizer que "nos setores onde a discriminação a ser superada se faz mais evidente e onde é constatado um quadro de desigualdade e de exclusão" (p. 186).

Para esses mesmos autores, o "objetivo da ação afirmativa é superar as desvantagens e desigualdade que atingem os grupos historicamente discriminados na sociedade brasileira e promover a igualdade entre os diferentes" (GOMES; MUNANGA, 2016, p. 187). Nesse sentido, foi criada a Lei no 10.639 (BRASIL, 2003) que incluiu no currículo oficial da rede de ensino a obrigatoriedade da temática "História e Cultura Afro-Brasileira". Porém, a criação de uma legislação não garante seu cumprimento e sua plena implementação na sociedade.

Como afirma Angela Davis (2016), na atualidade, em uma sociedade racista, não basta apenas não ser racista, é necessário ser antirracista. Essa afirmativa vale para a educação, assim como para todas as políticas públicas. Entre outras palavras, não basta que uma instituição de ensino desenvolva pequenas ações e simplórios projetos durante a semana da consciência negra e acredite que isso é suficiente para superar uma história única que é recontada durante séculos.

Não é levando uma roda de capoeira, uma baiana de acarajé ou provendo um desfile de beleza negra no mês de novembro que se está implementando a Lei 10.639/03 e construindo uma educação antirracista.

A superação do racismo e da naturalização das diferenças na vida social demanda a existência de um fazer educativo antirracista radical, ou como afirma Grosfoguel (2008), uma educação decolonial. Se no ambiente educacional fossem desenvolvidas atividades descolonizadas, a partir de uma matriz decolonial, que visassem combater e superar o racismo, se a discussão das relações étnico-raciais tivesse urgência e fosse entendida prioritária, não existiria tanta dificuldade para tratar um episódio de discriminação racial e, no melhor dos mundos, talvez esse caso nunca teria ocorrido. Entre outras palavras, a forma tradicional como a educação tem tratado a questão racial no Brasil faz com que ela sirva como um espaço de reprodução, e não de combate à prática do racismo.

Se analisarmos o caso dos estudantes com um pouco mais de atenção, será possível observar que a história única, o mito da democracia racial e a branquitude se relacionam e contribuíram pelo menos de duas formas para o ocorrido. A primeira é para a existência da própria prática racista. Os estudantes não inventaram o racismo no Brasil. O racismo é datado historicamente, sendo um fenômeno relativamente recente na trajetória humana (QUIJANO, 2014; GUIMARÃES, 1999), e se manifesta de diferentes formas em todos os lugares que foram dominados pela colonização (GOMES; MUNANGA, 2016).

Em nosso país, de uma forma velada ou mascarada (NASCIMENTO, 1978), práticas racistas têm sido um ingrediente estrutural para a composição de uma história triunfalista, de uma narrativa vencedora, cujo herói se faz na branquitude, e busca destruir outras possíveis.

As classificações e hierarquizações raciais serviram e servem para legitimar a dominação, e, como consequência direta, garantir a exploração (QUIJANO, 2005). O racismo é crucial para a construção de uma sociedade estamental, onde o status racial é demasiado importante para determinar o lugar social. O racismo e a história única formam o lado de uma mesma moeda, coexistindo-se em cooperação, em relação de nutrição contínua.

A discriminação racial praticada pelos estudantes é, na verdade, fruto da hegemonia de uma narrativa social excludente da qual fazem parte, porque são narrativas simbolicamente legitimadas e, por isso, sentem-se eles, meninos brancos, no direito de verbalizar, sabem que estão protegidos por um sistema que perpetua e, ao mesmo tempo, invisibiliza as desigualdades.

A segunda forma de a história única contribuir para a ocorrência do fato diz respeito, na abordagem de Guimarães (1999), à sobrevivência de um racismo "antirracista”, em aliança e sintonia com a crença da existência da já postulada democracia racial. Esse mito, constituinte da nossa nacionalidade, de um ideal de nação, serviu para aperfeiçoar a prática do racismo no país.

A construção de um novo discurso hegemônico sobre a miscigenação, a partir dos anos de 1930, foi essencial para uma mudança na construção da nacionalidade, que passa de racista heterofóbica para uma baseada no mito da democracia racial e no discurso de que somos todos brasileiros (GUIMARÃES, 1999), numa mistura perfeita e harmônica das raças, conforme Gilberto Freyre (1933) coloca em Casa Grande \& Senzala. 
O mito da brasilidade ajudou a criar uma nacionalidade que nasce de um projeto severamente elitista, que, segundo Guimarães (1999, p. 58), como não foi resultado das lutas populares, essa "nacionalidade não estendeu a cidadania a todos os brasileiros. Ao contrário, o imaginário aspirou - nas suas versões mais liberais - a uma raça mestiça que incorporasse negros e índios".

O racismo no Brasil se eterniza através de restrições fatuais da cidadania, assim como imposição de hierarquias que criam distâncias sociais e, segue dizendo Guimarães (1999, p. 59), "por demasiadas diferenças de renda e de educação, por meio de desigualdades sociais que separam brancos de negros, ricos de pobres, nordestinos de sulistas".

A questão que se coloca é que, a partir do mito da democracia racial, o racismo brasileiro se manifesta sem rosto, ou seja, ele se transveste e se apresenta diante de si mesmo como antirracismo, num discurso sub-reptício. Esse movimento fraudulento, portanto, impede a existência de narrativas periféricas, posto que elimina, ao mesmo tempo que escamoteia, as diferenças, apresentadas como elementos antinacionais.

Em outras palavras, o racismo no Brasil, primeiro ajuda a fundar o mito da democracia racial e depois sobrevive se nutrindo dessa crença, à medida que, ambos, fazem valer uma história única, uma história nacional, que nega a existência do racismo no país. Munido da história do vencedor, esse racismo se mascara, "tratando-se a si mesmo como antirracismo, e negando, como antinacional, a presença integral do afro-brasileiro ou do índio-brasileiro" (GUIMARÃES, 1999, p. 60).

Se existe uma narrativa que nega a existência do racismo no Brasil, a ação discriminatória daqueles estudantes pode ser descaracterizada. Um caso como esse pode ganhar novas leituras e interpretações, deixando de ser entendido como racismo para, por exemplo, serem interpretados como brincadeira de péssimo gosto, bullying ou simplesmente como "coisa" de adolescente.

O racismo só pode ser combatido se tivermos total consciência de sua existência, pois é impossível lutar contra aquilo que não existe (NASCIMENTO, 1978). Dessa forma, a superação do racismo no ambiente escolar exige tanto o reconhecimento de sua existência como uma postura firme na execução de ações, políticas, atividades e projetos educacionais antirracistas, papel importante dos educadores.

Na tentativa de solucionar o caso, a gestão do campus resolveu formar uma comissão para analisar a situação e estabelecer uma punição para os estudantes. Como sabiam que eu tinha ciência sobre o ocorrido, me convidou para participar da parte final desse trabalho, justamente a de penitência. Pensavam que eu arquitetaria uma punição severa, um castigo exemplar, discordei de supliciar os estudantes.

Em meu pensamento, se tinha alguém que deveria ser punido, naquele momento, esse alguém não poderia ser os estudantes. Assim, estabeleci um diálogo com o campus sobre quais atividades, projetos e ações referentes à implementação da Lei 10.639/03 que executavam. Não havia dúvida de que a escola também era responsável por aquela situação, pois a maioria dos profissionais desconhecia a lei. Ora, como punir estudantes se a escola não recebe nenhuma punição por não cumprir aquilo que a Constituição e as demais legislações tornam obrigatório?

Para esse caso, especificamente, o entendimento que eu tinha era de que os estudantes eram muito mais vítimas e suas ações discriminatórias eram consequências de uma estrutura racista, de um imaginário construído e que jamais fora desconstruído por toda a sociedade por onde circulavam, do que obra de desvios individuais de malfeitores mirins.

Individualizar o racismo, localizá-lo como um desvio de um ou outro indivíduo, também é uma forma de negar sua existência e seu poder estrutural. Individualizar significa corroborar para a permanência do mito da democracia racial e o enraizamento da narrativa dominante sobre as relações étnico-raciais no Brasil e também fugir das responsabilidades socioeducacionais.

Diante disso, como solução, propus a construção de um projeto de pesquisa sobre a implementação da Lei 10.639/03 nas escolas públicas de Primavera do Leste com a participação daqueles estudantes. Envergonhados, após o episódio, por serem taxados de racistas, os meninos não fizeram oposição à proposta, assim como os pais e responsáveis, que ficaram felizes ao saberem que os filhos não seriam "prejudicados" pelo cometimento de discriminação racial. 
De que adiantaria punir os autores se eles tinham a convicção de que não eram racistas e estavam dispostos a provar essa crença? Seus pais também tentavam provar a todo custo que os filhos não eram racistas e, para isso, utilizavam, até mesmo, argumentos racistas. $\mathrm{O}$ caminho para essa mudança passa sempre por uma educação antirracista.

Foi possível perceber que a ideia de serem racistas criou um incômodo para todos. Sabemos que, apesar de o racismo ser estrutural e dominante no país, por aqui, existe uma espécie de repúdio à racialização. Entre outras palavras, como aborda Guimarães (1999), somos racistas nas práticas, mas não toleramos a racialização por acreditar que é nela que reside o racismo. O fato é que, para se livrar da alcunha negativa, todos concordaram que o melhor caminho era participar de uma construção que extirpasse aquela amálgama.

A "punição" pedagógica aconteceu de forma frutífera durante dois anos, terminando quando os estudantes concluíram o ensino médio integrado na instituição. Tivemos vários resultados, nessa pesquisa, sendo que, além dos dois citados, outros 10 estudantes participaram desse e de outros projetos sobre a temática. O estudo gerou discussões, apresentações, publicações e, o mais importante, uma transformação na consciência dos dois e de muitos outros estudantes.

Atualmente, nosso grupo de pesquisa sobre a implementação da Lei 10.639/03 conta com quatro estudantes bolsistas e três voluntários. Com isso, continuo acreditando que a melhor punição para práticas racistas é o desenvolvimento e o convívio com práticas não racistas.

\section{Reflexões finais}

O diálogo proposto acima teve como base duas experiências vividas no seio da escola. A escolha não foi aleatória. Deveu-se ao fato de acreditar que a escola e a educação formal caminham de mãos dadas com a colonialidade.

A colonialidade foi produto, no início, de uma repressão sistemática não apenas de crenças, ideias, imagens, símbolos ou conhecimentos específicos que não serviram para a dominação colonial global.

Como vimos, a repressão recaiu principalmente sobre os modos de conhecer, de produzir conhecimento, de produzir perspectivas, imagens e sistemas de imagens, símbolos, modos de significação sobre os recursos, padrões e instrumentos de expressão formalizada e objetivada, intelectual ou visual (QUIJANO, 1992). Em seguida, houve um processo de imposição dos padrões dos dominantes. Por meio de um processo de sedução, por meio da mistificação de seus próprios padrões, os dominantes conseguiram fazer de sua cultura um padrão ou um modelo universal.

Ousamos afirmar que, historicamente, o ambiente escolar tem funcionado como uma grande vala comum, na qual sepultamos saberes, epistemes, sonhos, vidas e histórias.

Entre outras palavras, esse ambiente, que, para muitas pessoas é entendido como sinônimo de mudança, de transformação, de construção, de "evolução" e "progresso", para nós, tem sido também interpretado como um túmulo, em cuja lápide estão escritas as palavras pluralidade e diferença.

Em suma, a escola, ontem e hoje, no Brasil, tem estado a serviço da colonialidade, caracterizando-se como um espaço de eliminação, quando deveria ser de identidades, respeito e valorização das diferenças, pois a educação formal não é orientada por um currículo pluricultural.

O fazer da instituição escola tem sido a-histórico, cujas bases estão sedimentadas em práticas coloniais como classificações de corpos, hierarquizações de saberes e aniquilações de culturas. Assertivamente, a escola têm sido um lugar de reprodução de uma única narrativa. Um ambiente, por excelência, da reprodução de uma história única.

Sem espaços para diálogos com os diferentes, tem reproduzido narrativas triunfalistas que silenciam histórias em nome da continuidade da dominação. Nela, conta-se uma única narrativa vencedora, utilizando a naturalização da vida como mecanismo de legitimação.

Nilma Lino Gomes (1997) nos lembra que a denúncia sobre a contribuição da escola para a manutenção no Brasil de uma estrutura societal colonial excludente não é algo novo. Inclusive, os movimentos negros e 
seus pensadores já estão muito além da fase da denúncia da história única, mostrando que negros e negras, desde sempre, têm construído saberes, conhecimentos, epistemologias e pensamentos que são próprios de suas raízes e experiências raciais, todavia, toda essa gama de conhecimento não tem espaço na educação formal.

A compreensão da cidadania no Brasil tem sido algo tão complexo, e, apesar dos avanços dos estudos periféricos - ou seja, os estudos que estão à margem -, a escola não tem conseguido dialogar com a pluralidade, com a diversidade e, sobretudo, com a diferença.

É premente um fazer pedagógico radical, ou seja, decolonial, que possa contribuir para um entendimento do mundo para além da visão hegemônica. É preciso identificar e enquadrar as narrativas dominantes e triunfalistas que imperam no cotidiano das escolas brasileiras. É necessário desmistificar, dissecar, desconcertar e destruir essas narrativas nocivas e opressoras.

É urgente a descolonização do nosso pensamento e de nossas ações na escola e na vida. Devemos romper com os currículos tradicionais, homogêneos, hierarquizantes, opressivos e autoritários. Portanto, o currículo dominante não é neutro, natural ou isento; posto que é um documento histórico repleto de intencionalidades, usado na e para forjar identidades.

E foi justamente este o nosso intuito neste estudo: refletir sobre o racismo e a história única que impera na educação brasileira, a partir de uma discussão teórica sobre duas experiências vividas pelo pesquisador, como professor negro, em duas escolas de diferentes regiões brasileiras: a escola quilombola Colégio Estadual Onildo Raimundo de Cristo (BA) e o Instituto Federal de Educação, Ciência e Tecnologia de Mato - campus Primavera do Leste (MT). Pudemos apreender em ambas as experiências que devemos superar a colonialidade existente na educação, promovendo um fazer decolonial que possa ser construído para além de uma história única.

O que vislumbro como educador é pavimentar o chão da escola com projetos de educação baseados na diversidade, na pluralidade e no respeito que contribuam para o entendimento da sociedade brasileira para além das visões simplistas, reducionistas e estereotipadas.

Importa lutar por uma educação descolonizada, ou seja, fundamentada a partir de uma matriz decolonial, que estimule o conviver de forma saudável com a diferença. Dessa forma, o sonho de viver um mundo em que outros mundos sejam possíveis pode se tornar uma grandiosa aventura pelo caminho do conhecimento e das vivências múltiplas.

\section{Referências}

ADICHIE, Chimamanda Ngozi. O perigo de uma história única. São Paulo: Companhia das Letras, 2019.

BENJAMIN, Walter. Sobre o Conceito de História. In: BENJAMIN, Walter. Obras Escolhidas: magia e técnica, arte e política. São Paulo: Brasiliense, 1985. p. 222-232.

BRASIL. Lei $\mathrm{n}^{\circ}$ 10.639, de 6 de janeiro de 2003. Altera a Lei $\mathrm{n}^{\circ}$ 9.394, de 20 de dezembro de 1996, que estabelece as diretrizes e bases da educação nacional, para incluir no currículo oficial da Rede de Ensino a obrigatoriedade da temática "História e Cultura Afro-Brasileira", e dá outras providências. Diário Oficial da União: seção 1, Brasília, DF, p. 1, 10 jan. 2003.

CARVALHO, José Murilo de. Cidadania no Brasil: o longo caminho. 2. ed. Rio de Janeiro: Civilização Brasileira, 2002.

CONRAD, Sebastian. What is global history? Princeton: Princeton University Press, 2016.

DAVIS, Angela. Mulheres, raça e classe. São Paulo: Boitempo, 2016.

FONSECA, Dagoberto José. Você conhece aquela? São Paulo: Selo Negro Edições, 2012

FREIRE, Paulo. Pedagogia da esperança. São Paulo: Paz e Terra, 2014.

FREIRE, Paulo. Pedagogia do oprimido. 17. ed. Rio de Janeiro: Paz e Terra, 1987.

FREYRE, Gilberto. Casa-Grande \& Senzala: formação da família brasileira sob o regimen de economia patriarchal. Rio de Janeiro: Maia \& Schimidt, 1933. 
GOMES, Nilma Lino. A contribuição dos negros para o pensamento educacional brasileiro. In: SILVA, Petronilha Beatriz Gonçalves e; BARBOSA, Lucia Maria de Assunção (org.). O pensamento negro em educação no Brasil. São Carlos: EDUFSCar, 1997. p. 17-30.

GOMES, Nilma Lino; MUNANGA, Kabengele. O negro no Brasil de hoje. São Paulo: Global, 2016.

GROSFOGUEL, Ramón. Para descolonizar os estudos de economia política e os estudos pós-coloniais: transmodernidade, pensamento de fronteira e colonialidade global. Revista Crítica de Ciências Sociais, Coimbra, v. 80, p. 115-147, mar. 2008.

GUIMARÃES, Antonio Sérgio Alfredo. Racismo e antirracismo no Brasil. São Paulo: Editora 34, 1999.

MIGNOLO, Walter. Colonialidade: o lado mais escuro da modernidade. Revista brasileira de Ciências Sociais, São Paulo, v. 32, n. 94, e329402, jun. 2017.

NASCIMENTO, Abdias do. Genocídio do negro brasileiro: processo de racismo mascarado. Rio de Janeiro: Editora Paz e Terra, 1978.

QUIJANO, Aníbal. Colonialidad y Modernidad/Racionalidad. Peru Indígena, Lima, v. 13, p. 11-20, 1992.

QUIJANO, Aníbal. Colonialidade do poder, eurocentrismo e América Latina. Buenos Aires: CLACSO, 2005. Disponível em: http://bibliotecavirtual.clacso.org.ar/clacso/sur-sur/20100624103322/12_Quijano.pdf. Acesso em: 15 nov. 2019.

QUIJANO, Aníbal. “Raza”, “Etnia” y “Nación” em Mariátegui. In: QUIJANO, Aníbal (org.). Cuestiones y horizontes: de la dependencia histórico-estructural a la colonialidad/descolonialidad del poder. Buenos Aires: Clacso, 2014. p. 757-775.

RIBEIRO, Djamila. Lugar de fala. São Paulo: Sueli Carneiro: Pólen, 2019.

SANTOS, Boaventura de Sousa. Para além do pensamento abissal: das linhas globais a uma ecologia dos saberes. In:SANTOS, Boaventura de Sousa; MENESES, Maria Paula (org.). Epistemologias do Sul. Coimbra: Edições Almedina, 2009. p. 23-71.

Data de submissão: 12/06/2020

Data de aceite: $27 / 07 / 2020$ 